\title{
PENERAPAN TERAPI SENI DALAM MENGURANGI KECEMASAN PADA PEREMPUAN KORBAN KEKERASAN DALAM RUMAH TANGGA DI JAKARTA
}

\author{
Mario Carl Joseph ${ }^{1}$, Monty P. Satiadarma ${ }^{2}$, dan Rismiyati E. Koesma ${ }^{3}$ \\ ${ }^{1}$ Fakultas Psikologi, Universitas Tarumanagara Jakarta \\ Email : josephmariocarl@gmail.com \\ ${ }^{2}$ Fakultas Psikologi, Universitas Tarumanagara Jakarta \\ Email : monty_satiadarma@yahoo.com \\ ${ }^{3}$ Fakultas Psikologi, Universitas Tarumanagara Jakarta \\ Email : ristetty@gmail.com
}

\begin{abstract}
ABSTRAK
Kekerasan dalam rumah tangga adalah bentuk kekerasan yang paling banyak dialami oleh perempuan berusia 25 - 40 tahun. Kecemasan merupakan salah satu bentuk reaksi emosional yang menyertai perempuan ketika mengalami kekerasan dalam rumah tangga. Kecemasan pada perempuan yang menjadi korban kekerasan dalam rumah tangga diukur dengan Hamilton Anxiety Rating Scale (HARS) dan melihat gejala kecemasan dari segi kognitif, somatis, motorik dan afektif. Penelitian ini menggunakan metode kualitatif untuk menggambarkan kecemasan dan metode kuantitatif untuk melihat penurunan tingkat kecemasan dengan terapi seni pada perempuan korban kekerasan dalam rumah tangga. Subyek penelitian ini adalah dua perempuan yang telah bercerai dan mengalami kekerasan dalam rumah tangga dalam bentuk fisik, seksual, psikis atau verbal dan penelantaran rumah tangga. Teknik pengambilan sampel dengan menggunakan metode purposive sampling. Pemberian terapi seni pada masing-masing subyek dilakukan sebanyak tujuh sesi. Dalam penelitian ini, terapi seni telah terbukti dapat mengurangi kecemasan pada perempuan korban kekerasan dalam rumah tangga dengan menunjukan perubahan tingkat kecemasan sebelum dan sesudah intervensi. Keberhasilan terapi seni ini juga dipengaruhi oleh adanya kesadaran pada masing-masing subyek untuk konsisten menjalani terapi.
\end{abstract}

Kata Kunci: Terapi seni, kecemasan, KDRT

\section{PENDAHULUAN}

Kekerasan dalam rumah tangga telah diakui sebagai masalah sosial di seluruh dunia (Haguedan Mullender, 2006) dan merupakan salah satu penyebab utama terjadinya cedera pada korban (Griffin dan Koss, 2002). Fenomena terjadinya kekerasan dalam rumah tangga di Indonesia menurut Kepala Badan Pusat Statistik Suhariyanto (dalam Handayani, 2017), sebanyak 36,3 persen perempuan di kota mengalami berbagai bentuk kekerasan baik dari pasangan maupun bukan pasangan sebagai akibat dari tekanan hidup di kota yang lebih tinggi sehingga orangorang lebih cepat marah dan melampiaskan kemarahan kepada perempuan.

Pada tahun 2017, berdasarkan Catatan Tahunan (CATAHU) Komnas Perempuan kekerasan di ranah rumah tangga/relasi personal, kekerasan terhadap istri (KTI) menempati peringkat pertama 5.784 kasus (56\%). Ranah personal artinya pelaku adalah orang yang memiliki hubungan darah (ayah, kakak, adik, paman, kakek), kekerabatan, perkawinan (suami) maupun relasi intim (pacaran) dengan korban. Menurut data yang dihimpun oleh Komnas Perempuan, mayoritas korban di ranah personal ada di rentang usia 25-40 tahun.

Menurut Pasal 1 dari Undang-Undang No. 23 Tahun 2004 tentang Penghapusan Kekerasan dalam Rumah Tangga (PKDRT), kekerasan dalam rumah tangga adalah setiap perbuatan terhadap seseorang terutama perempuan, yang berakibat timbulnya kesengsaraan atau penderitaan secara fisik, seksual, psikologis, dan/atau penelantaran rumah tangga termasuk ancaman untuk melakukan perbuatan, pemaksaaan, atau perampasan kemerdekaan secara melawan hukum dalam lingkup rumah tangga. Bentuk kekerasan dalam rumah tangga menurut 
pasal 5 dari UU No.23 tahun 2004 adalah : 1) Kekerasan Fisik; 2) Kekerasan Psikis; 3) Kekerasan Seksual; 4) Penelantaran rumah tangga.

Kekerasan dalam rumah tangga dapat menyebabkan cedera fisik dan masalah mental. Beberapa dari cedera fisik yang bisa terjadi meliputi luka, memar, bekas gigitan, gegar otak, patah tulang, keguguran, kerusakan sendi, kehilangan pendengaran dan penglihatan, migrain, disfigurement permanen, arthritis, hipertensi, penyakit jantung dan infeksi menular seksual termasuk human papillomavirus yang dapat menyebabkan kanker serviks dan akhirnya kematian (Abbot \& Williamson, 1999; Coker,Hopenhayn, DeSimone, Bush, \& Crofford, 2009; McCaw,Golding, Farley, \& Minkoff, 2007). Beberapa masalah kesehatan mental yang bisa terjadi dari kekerasan dalam rumah tangga termasuk depresi, alkohol atau penyalahgunaan zat, kecemasan, gangguan kepribadian, gangguan stres pasca trauma, gangguan makan dan tidur, disfungsi sosial, dan bunuh diri (Abbot \& Williamson,1999; Gerlock, 1999; Howard, Trevillion, \& AgnewDavies,2010; McCaw dkk., 2007).

Penelitian yang dilakukan oleh Alexander (2000) mengemukakan bahwa perempuan yang selalu menahan perasaan dan memendam gejolak batinnya akan cenderung mengarahkan kemarahannya ke dalam diri sehingga menimbulkan rasa takut dan cemas yang berujung pada depresi. Kecemasan menurut Spielberger (1972) merupakan reaksi emosional yang tidak menyenangkan terhadap bahaya nyata atau imajiner yang disertai dengan perubahan sistem syaraf otonom dan pengalaman subjektif sebagai "tekanan", "ketakutan" dan "kegelisahan". Sedangkan menurut Atwater (1983), kecemasan merupakan perasaan tidak nyaman dan ancaman bahwa sesuatu yang buruk akan terjadi.

Pada kasus kekerasan, terdapat berbagai bentuk pendekatan dan metode dalam terapis psikologis, salah satu yang digunakan adalah terapi seni. Malchiodi (2001), mengatakan bahwa terapi seni dapat memberikan relaksasi pada individu yang mengalami kasus kekerasan. Talwar (2007) membahas manfaat terapi seni dalam mengakses memori traumatik nonverbal dan membantu pemulihan trauma. Terapi seni dapat menghubungkan aspek memori di otak dan membantu dalam memproses kenangan trauma somatik. Selain bersifat relaksasi, mengakses memori traumatik non verbal, terapi seni dinilai juga bisa mengungkapkan perasaan, pikiran, dan hal-hal yang menganggu secara non verbal (Malchiodi, 2003).

Pada penelitian ini mengambil subyek perempuan yang pernah mengalami kekerasan dalam rumah tangga (KDRT) di Jakarta. Kecemasan sebagai dampak dari kekerasan dalam rumah tangga seringkali juga dialami oleh subyek MP dan MR. Penelitian tentang penerapan terapi seni untuk mengurangi kecemasan pada perempuan korban kekerasan dalam rumah tangga di Jakarta juga masih sangat sedikit ditemukan dalam literatur. Untuk itu penulis tertarik untuk melakukan penelitian dengan terapi seni dalam mengurangi kecemasan pada perempuan korban KDRT di Jakarta.

\section{LANDASAN TEORI}

\section{Kekerasan Dalam Rumah Tangga}

Pasal 1 UU No.23 Tahun 2004 (dalam Poerwandari dan Lianawati, 2010), menjelaskan bahwa kekerasan dalam rumah tangga adalah setiap perbuatan terhadap seseorang terutama perempuan, yang berakibat timbulnya kesengsaraan atau penderitaan secara fisik, seksual, psikologis, dan/atau penelantaran rumah tangga termasuk ancaman untuk melakukan perbuatan, pemaksaan, atau perampasan kemerdekaan secara melawan hukum dalam lingkup rumah tangga. 


\section{Kecemasan}

Menurut Spielberger (1972), kecemasan adalah reaksi emosional yang tidak menyenangkan terhadap bahaya nyata atau imaginer yang di sertai dengan perubahan pada sistem saraf otonom dan pengalaman subjektif sebagai "tekanan", "ketakutan", dan "kegelisahan".

\section{Terapi Seni}

Margaret Naumburg dan Edith Kramer (dalam Rubin, 2010) memiliki pandangan yang berbeda melihat seni dalam art therapy. Margaret Naumburg melihat seni sebagai bentuk ungkapan simbolis, datang dari alam bawah sadar seperti mimpi, untuk ditimbulkan secara spontan dan dipahami melalui asosiasi bebas. Oleh karena itu, pembuatan karya seni, menjadi dikenal di bidang terapi seni sebagai pendekatan yang berfokus pada "produk", dan disebut sebagai "seni dalam terapi" atau terapi psikoterapis yang berbeda dengan "proses", atau "seni sebagai terapi", yang menekankan proses kreatif itu sendiri sebagai penyembuhan (Rappaport, 2009).

Edith Kramer melihat seni sebagai bentuk sublimasi, yaitu cara menyatukan perasaan dan dorongan yang saling bertentangan dalam sebuah bentuk estetis melalui proses kreatif. Dalam art therapy, terapis membantu klien untuk menyalurkan emosi melalui pengalaman proses pembuatan karya seni (Landgarten, 1981). Freud (dalam Feist dan Feist, 2008) mengatakan bahwa sublimasi merupakan penyaluran emosi melalui hal-hal yang bisa diterima, baik secara kultural ataupun sosial. Freud mengatakan bahwa karya seni Michaelangelo merupakan contoh dari sublimasi.

Rappaport (2009) mengatakan bahwa terapi seni juga mencakup seni visual, proses kreatif dan psikoterapi untuk meningkatkan kesejahteraan secara emosional, kognitif, fisik dan spiritual. Sejalan dengan itu, Landgarten (1981) menjelaskan bahwa aspek nonverbal dalam psikoterapi seni memegang posisi penting dan unik dalam kesehatan mental. Aspek nonverbal dan psikoterapi memberi kesempatan kepada partisipan untuk "mendengarkan dengan mata" mereka. Sebagai contoh ketika masyarakat terus menerus disajikan dengan informasi yang dapat dilihat melalui iklan dalam media komunikasi seperti telivisi. Masyarakat dengan bebas menentukan iklan yang tidak ingin mereka lihat dan menggantinya dengan iklan lain yang lebih mereka sukai.

Berdasarkan definisi di atas, terapi seni adalah suatu bentuk ungkapan simbolis dan cara menyalurkan emosi melalui pengalaman proses pembuatan karya seni untuk meningkatkan kesejahteraan secara emosional, kognitif, fisik dan spiritual.

\section{METODE PENELITIAN}

Subyek dalam penelitian ini memiliki karakteristik : (a) Jenis kelamin perempuan; (b) Usia 20 - 40 tahun; (c) Mengalami kecemasan dalam bentuk kognitif; motorik, somatis dan afektif; (d) Mengalami kekerasan dalam bentuk fisik, seksual, psikis dan penelantaran rumah tangga. Pada penelitian ini ada dua subyek yaitu MP (36 tahun) dan MR (38 tahun).

Berdasarkan sifat penyelidikan (the nature of the investigation), penelitian ini adalah single quasi experimental atau case studies dengan menggunakan teknik purposive sampling design (Kumar, 1996). Pertimbangan utama dalam purposive sampling adalah penilaian peneliti terhadap partisipan yang dapat memberikan informasi terbaik untuk mencapai tujuan penelitian. Peneliti hanya pergi ke orang-orang yang cenderung memiliki informasi yang dibutuhkan dan bersedia membaginya. Setelah peneliti menemukan partisipan sesuai dengah kriteria yang 
dibutuhkan dalam penelitian, selanjutnya peneliti mengumpulkan data dengan cara memberikan kuesioner, melakukan pengamatan (observation) dan wawancara (interview).

Beberapa contoh pertanyaan dalam panduan wawancara, yaitu : (a) Kapan pertama kali anda mengalami kekerasan dalam rumah tangga ?; (b) Apa bentuk kekerasan dalam rumah tangga yang anda alami ?; (c) Apa dampak kekerasan dalam rumah tangga terhadap kehidupan seharihari ?; (d) Apa perasaan anda ketika pertama kali mengalami kekerasan dalam rumah tangga ?

Penelitian ini menggunakan pendekatan metode kualitatif sebagai metode utama dan metode kuantitatif sebagai metode pendukung. Metode kualitatif digunakan untuk memberikan gambaran kecemasan yang dialami perempuan korban kekerasan dalam rumah tangga. Metode kuantitatif melalui pre-post test digunakan untuk melihat peran terapi seni dalam mengurangi kecemasan. Pengukuran kecemasan dalam penelitian ini menggunakan kuesioner dari alat ukur Hamilton Anxiety Rating Scale (HARS). Skala HARS merupakan pengukuran kecemasan yang didasarkan pada munculnya gejala pada individu yang mengalami kecemasan.

Dalam setiap sesi, ahli terapi seni klinis menawarkan teknik, materi pelajaran, media dan / atau pilihan bebas yang sesuai dengan perubahan kebutuhan dan sasaran terapeutik partisipan (Landgarten, 1981). Dengan kebebasan yang diberikan kepada partisipan untuk memilih lokasi diharapkan partisipan akan merasa lebih nyaman sehingga program intervensi dapat berjalan dengan maksimal. Penelitian ini juga menggunakan beberapa alat bantu, yaitu: (a) Pedoman wawancara; (b) Alat perekam (tape recorder); (c) Alat tulis; (d) Media terapi seni.

\section{HASIL DAN PEMBAHASAN}

Intervensi ini dibuat berdasarkan referensi dari Barbara Ganim (1999). Ganim memiliki empat tahapan dasar dalam melakukan art therapy, yaitu : (a) Expressing your emotions; (b) Healing the mind; (c) Healing the body; (d) Transformation of the spirit. Program ini terdiri atas tujuh sesi, di mana setiap sesi berkisar antara 90 - 120 menit.

\section{Gambaran Pelaksanaan Program Intervensi}

Terapi seni pada perempuan korban kekerasan dalam rumah tangga ini akan dilakukan selama kurang lebih 1 bulan dengan satu minggu 4 kali pertemuan. Setiap pertemuan akan berlangsung selama 90 - 120 menit. Sesi pertama adalah proses screening apakah partisipan memiliki kriteria yang sesuai dengan kategori penelitian. Pada sesi kedua, peneliti memberikan informed consent kepada partisipan yang mengalami kecemasan dan dilanjutkan dengan memberikan Hamilton Anxiety Rating Scale (HARS) untuk melihat tingkat kecemasan (pre-test) partisipan sebelum dilaksanakannya program intervensi. Peneliti kemudian memperkenalkan art material yang akan digunakan dalam proses terapi dan di awali dengan menggambar bebas.

Pada sesi ketiga, merupakan tahap pertama dari program intervensi, yaitu expressing your emotion. Tahap pertama bertujuan untuk membantu partisipan menjelaskan masalah yang dialami dan menunjukan bagaimana cara melewati masalah tersebut. Pada sesi keempat, merupakan tahap kedua dari program intervensi yaitu healing the mind. Tahap ini membantu partisipan untuk dapat keluar dari masalah yang dialaminya. Hal ini sejalan dengan terapi seni yang telah dijelaskan oleh Levick (1981) bahwa terpai seni bermanfaat sebagai media katarsis.

Pada sesi kelima, merupakan tahap ketiga dari program intervensi yaitu healing the body. Tahap ini bertujuan untuk memperkuat insight partisipan akan hal-hal positif dalam dirinya. Pada sesi keenam, merupakan tahap keempat dari program intervensi yaitu transformation of the spirit. 
Tahap ini bertujuan untuk memberikan kesempatan kepada partisipan untuk mengekspresikan perubahan positif dan membantu partisipan agar lebih sadar akan perubahan positif dalam dirinya.

Sesi ketujuh, peneliti memasuki tahap terminasi dan melakukan evaluasi pelaksanaan program intervensi. Selanjutnya, peneliti memberikan alat ukur kecemasan (HARS) kepada partisipan. Partisipan diminta untuk mengisi HARS dengan menggunakan pensil atau pulpen. Dalam tahap ini, peneliti juga meminta partisipan menggambar mengenai pengalaman positif dan harapan yang telah ia temukan selama menjalani proses penyembuhan dengan terapi seni.

Berdasarkan alat ukur Hamilton Anxiety Rating Scale (HARS) diketahui bahwa adanya penurunan kecemasan pada masing-masing partisipan. Gambaran penurunan kecemasan dapat dilihat pada tabel berikut.

Tabel 1 Gambaran Total Nilai Tingkat Kecemasan Sebelum dan Sesudah Mengikuti Sesi Intervensi Pada Kedua Subyek

\begin{tabular}{ccccc}
\hline & Pretest MP & Posttest MP & Pretest MR & Posttest MR \\
\hline Kecemasan & 30 & 15 & 31 & 18 \\
\hline
\end{tabular}

Dari hasil tabel diatas, dapat dilihat bahwa adanya penurunan kecemasan pada masing-masing partisipan. Pada partisipan MP, total nilai pada pengukuran kecemasan sebelum mengikuti intervensi adalah 30. Menurut Hamilton (1959), total nilai dari 14 item yang dimiliki oleh individu setidaknya memiliki rentan 28 - 41 agar dapat dikatakan bahwa individu tersebut memiliki tingkat kecemasan berat. Kemudian setelah mengikuti intervensi, total nilai kecemasan MP adalah 15, yang berada pada rentan 14 - 20 sehingga dapat dikatakan MP memiliki tingkat kecemasan ringan.

Pada partisipan MR, total nilai pada pengukuran kecemasan sebelum mengikuti intervensi adalah 31. Menurut Hamilton (1959), total nilai dari 14 item yang dimiliki oleh individu setidaknya memiliki rentan 28 - 41 agar dapat dikatakan bahwa individu tersebut memiliki tingkat kecemasan berat. Kemudian setelah mengikuti intervensi, total nilai kecemasan MR adalah 18, yang berada pada rentan $14-20$ sehingga dapat dikatakan MR memiliki tingkat kecemasan ringan. 


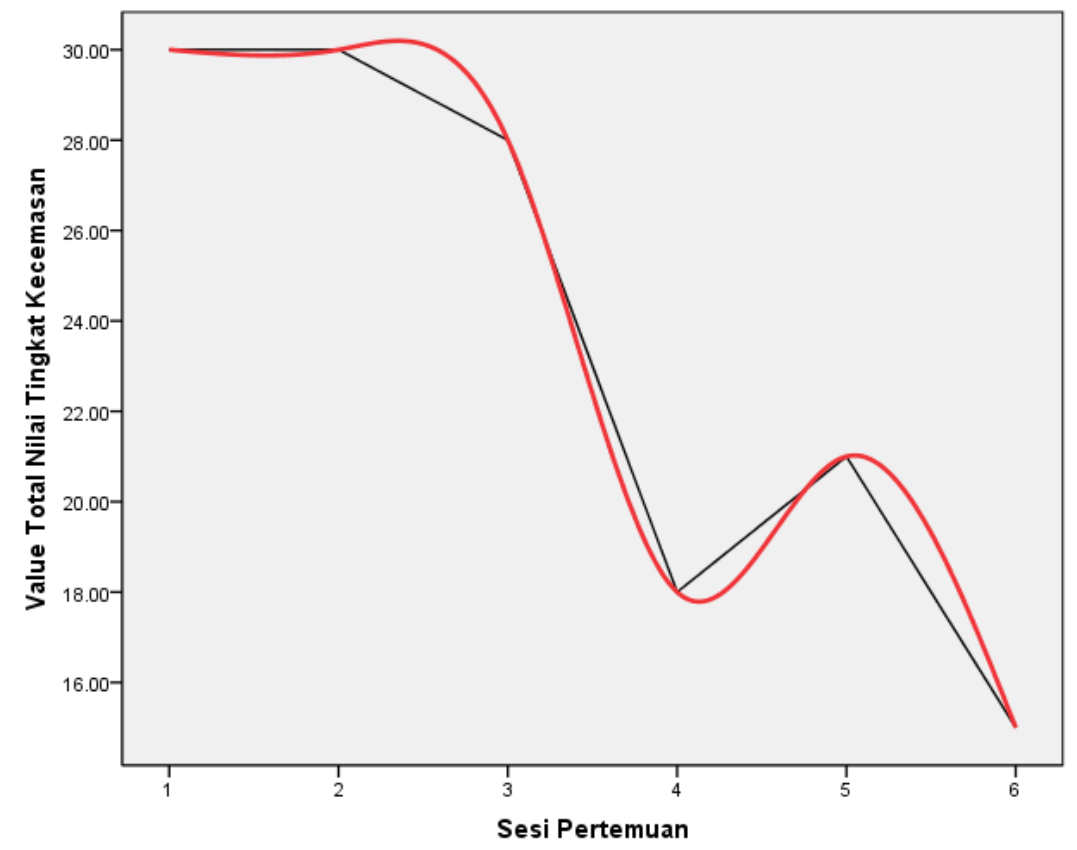

Grafik 1 Penurunan kecemasan subyek MP

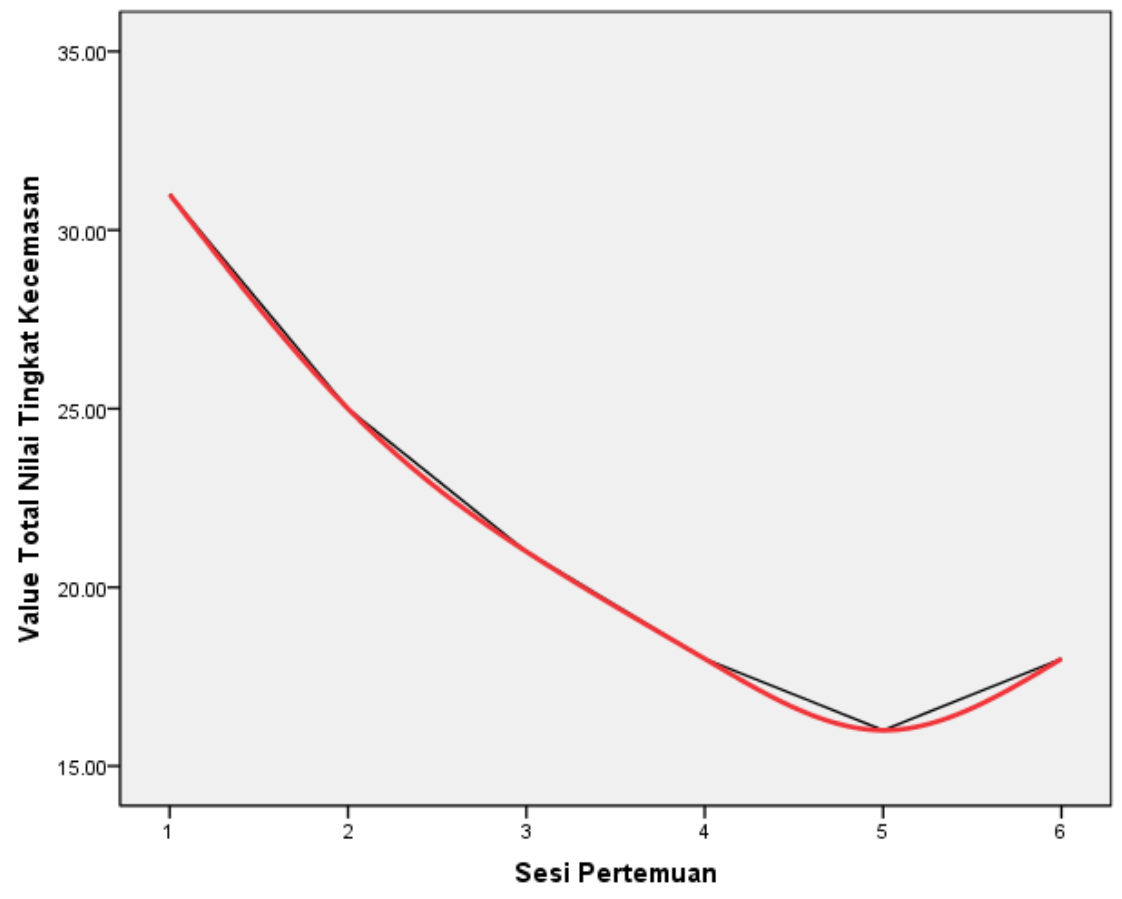

Grafik 2 Penurunan kecemasan subyek MR

Dari grafik penurunan kecemasan pada partisipan MP dan partisipan MR, diketahui bahwa sesi terapi seni yang diberikan kepada kedua partisipan dapat mengurangi kecemasan.

\section{Kesimpulan}


Berdasarkan hasil intervensi terapi seni yang dijalani oleh kedua subyek maka dapat disimpulkan bahwa intervensi terapi seni dapat mengurangi kecemasan pada perempuan korban kekerasan dalam rumah tangga. Kesimpulan ini dilandasi oleh adanya pengurangan total nilai kecemasan pada masing-masing partisipan. Total nilai kecemasan MP adalah 30 untuk nilai pretest dan 15 untuk nilai posttest. Sedangkan total nilai kecemasan MR adalah 31 untuk nilai pretest dan 18 untuk nilai posttest.

Target dari penelitian ini adalah ingin mengurangi kecemasan dengan menggunakan penerapan art therapy pada perempuan korban kekerasan dalam rumah tangga. Bukti-bukti yang diperoleh dari kedua partisipan menunjukan adanya perubahan total nilai kecemasan dan perubahan respon dari 14 item gejala kecemasan. Dengan demikian, penerapan terapi seni telah mampu mengurangi kecemasan pada masing-masing partisipan.

Hal ini sejalan dengan Ganim (1999) yang menjelaskan bahwa kebanyakan dari kita telah diajarkan untuk berpikir bahwa emosi yang menyakitkan adalah emosi yang buruk dan sesuatu yang lebih baik kita hindari atau abaikan. Dalam tahap kedua yaitu healing the mind dan tahap ketiga yaitu healing the body, masing-masing partisipan menyadari bahwa setiap emosi yang dapat dirasakan merupakan hal penting untuk kelangsungan hidup. Masing-masing partisipan juga menyadari bahwa kondisi jiwa yang sehat berarti mengambil tanggung jawab atas bagaimana partisipan memikirkan, merasakan, bereaksi dan memproses emosi yang dimilikinya. Tahap ini merupakan bentuk sublimasi dan eskplorasi dari energi psikis dalam bentuk seni.

\section{Diskusi}

Dalam penelitian ini, alat ukur yang digunakan adalah Hamilton Anxiety Rating Scale yang mengukur tingkat kecemasan dengan mengetahui total nilai dari 14 item respon kecemasan secara umum, seperti adanya perasaan cemas, ketegangan, ketakutan, gangguan tidur; gangguan kecerdasan, perasaan depresi, gejala otot, gejala sensorik, gejala kardiovaskuler, gejala respiratori, gejala gastrointestinal, gejala urogenital, gejala autonomy dan tingkah laku. Namun, penelitian ini akan lebih baik lagi jika mengukur post traumatic stress disorder dari masing-masing partisipan.

Bagi peneliti yang ingin menerapkan terapi seni sebagai bentuk intervensi dapat memperhatikan status pernikahan, usia anak sebagai karakteristik partisipan, lama perceraian dan kemampuan dari terapis agar penerapan intervensi terapi seni dapat dilakukan dan berhasil. Karakteristik partisipan dan kemampuan terapis dapat menentukan keberhasilan pelaksanaan sesi intervensi.

Penelitian selanjutnya dapat memperhatikan jumlah sesi yang diberikan. Jumlah sesi dapat disesuaikan dengan metode terapi seni serta permasalahan dari masing-masing partisipan. Sebagai contoh pada kasus post traumatic stress disorder korban kekerasan dalam rumah tangga semakin lama sesi intervensi akan memberikan hasil yang lebih maksimal. Jumlah subyek dalam penelitian selanjutnya perlu ditambah. Hal ini dikarenakan semakin banyak jumlah subyek maka semakin bervariasi pula hasil yang akan diperoleh sehingga aspek-aspek psikologis lain yang tampak dapat diobservasi dalam proses terapi dan dapat dijadikan bahasan diskusi pada hasil penelitian.

\section{Saran}

Saran Bagi MP 
Saran bagi MP adalah untuk tetap melatih konsistensi dan kemampuan konsentrasi ketika menyelesaikan suatu pekerjaan. MP juga perlu menyadari bahwa mencintai diri sendiri adalah hal utama sebelum MP mencintai orang lain.

MP juga perlu belajar untuk berani menceritakan permasalahan kepada orang lain agar tidak menjadi cemas. Kegiatan melukis dan berolahraga dapat dijadikan sebagai media untuk menyalurkan emosi dan mencegah MP mengalami kecemasan.

Saran Bagi MR

Saran untuk MR adalah tetap melanjutkan konseling dengan psikolog agar dapat membantunya melewati masa-masa sulit. Peran keluarga khususnya Ayah dan Ibu sangat penting untuk saat ini agar MR memiliki kepercayaan diri.

\section{Ucapan Terima Kasih (Acknowledgement)}

Penelitian ini dilakukan dengan bantuan, dukungan dan masukan dari berbagai pihak. Oleh karena itu, peneliti mengucapkan terima kasih dengan tulus kepada semua pihak yang memberikan kontribusinya dalam penelitian ini, antara lain : 1) Dr. Monty P. Satiadarma, Psikolog, dan Dr. Rismiyati E. Koesma, Psikolog atas waktu bimbingan dan diskusinya; 2) Bapak Susanto Joseph (alm) dan Ibu Magdalena Joseph selaku orang tua yang tiada hentinya memberikan dukungan materi dan doa; 3) Responden penelitian, subyek MP dan MR atas kesediaannya untuk berpartisipasi dalam penelitian ini.

\section{REFERENSI}

Abbot, P., \& William, E. (1999). Women, Health and Domestic Violence. Journal of Gender Studies, Vol. 8, No. 1, pp. 83-102.

Adriani, S. N. \& Satiadarma, M. P. (2011). Efektifitas art therapy dalam mengurangi kecemasan pada remaja pasien leukemia. Indonesian Journal of Cancer Vol. 5 No.1, 31 -47.

Alavinezhad, R., Mousavi, M., \& Sohrabi, N. (2014). Effects of art therapy on anger and self-esteem in aggressive children. Procedia - Social and Behavioral Sciences, 113 ,

$111-117$.

Anggoman, Y., \& Wirawan, H. E. (2002). Dampak Psikologis Kekerasan Fisik Di

Dalam Rumah Tangga. Jurnal Psikologi. Tahun VII, No.2.

Atkinson, R., Richard, A., Hilgard, E. 1996. Introduction to psychology. New York:

Harcourt Brace College Publishers.

Atwater, E. (1983). Psychology of Adjustment : Personal Growth In A Changing World. 2nd. Ed.

New Jersey : Prentice-Hall.

Avdibegović, E., \& Sinanović, O. (2006). Consequences of domestic violence on women's mental health in Bosnia and Herzegovina. Croat Med J. 2006;47:730-41.

Beirne, P., \& Messerscmidt, J. W. (1995). Criminology. 2nd ed. New York : Harcourt.

Bjelland, I. (2002). The validity of the hospital anxiety and depression scale.

Psychomatic journal,52(2), 66-77. Retrieved from

http://www.ncbi.nlm.nih.gov/pubmed/11832252

Bourne, E. J. (2005). The anxiety \& phobia workbook (4th ed.). Oakland, CA: New Harbinger Publications.

Buchalter, S. I. (2009). Art therapy techniques and application. London: Jessica Kingsley Publisher. 
Cahya, D. K. (2015). Kasus KDRT di Jakarta Tinggi, Kenapa ? Retrieved from http://megapolitan.kompas.com/read/2015/04/14/15105451/Kasus.KDRT.di.Jakarta.Tinggi.K enapa

Carducci, Bernado J. (2009). The Psychology of Personality: Viewpoints, Research, and Applications 2nd Ed. John Wiley \& Sons, Ltd. Publication.

Case, C., \& Dalley, T. (1992). The Handbook of Art Therapy. Hove and New York, BrunnerRoutledge.

Creswell, J. W. (2007). Qualitative inquiry and research design: choosing among five approaches.

Second edition. London:Sage.

Dobash,R.E.,\& Dobash, R. (1979). Violence Against Wives:A Case Againts the Patriarhhy.New York:The Free Press.

Ellingson, M. (1991). A philosophy for clinical art therapy. In H. B. Landgarten \& D. Lubbers (Eds.), Adult art psychotherapy: Issues and applications. (pp. 3-20). New York, NY: Brunner/Mazel.

Edwards, D. (2004). Art Therapy. Sage Publications. London.

Feist, J. \& Feist, G. J. (2008). Teori Kepribadian. Edisi 7. Jakarta: Salemba Humanika.

Ganim, B. (1999). Art and Healing: Using Expressive Art to Heal Your Body, Mind and Spirit. New York, NY: Three Rivers Press.

Gerlock, A. A. (1999). Health impact of domestic violence. Issues in Mental Health Nursing, 20 , 373-385.

Griffin, M. P., \& Koss, M. P. (2002). Clinical Screening and Intervention in Cases of Partner Violence. Online Journal of Issues in Nursing. Vol. 7 No. 1. Retrieved from http://www.nursingworld.org/MainMenuCategories/ANAMarketplace/ANAPeriodicals/OJIN/ TableofContents/Volume72002/No1Jan2002/ClinicalScreeningandPartnerViolence.aspx Haber, A., \& Runyon, R.P. (1984). Psychology of Adjustment. Illinois : The Dorsey Press. Hague, Gill \& Mullender, Audrey. (2006). Who Listens? The Voices of Domestic Violence Survivors in Service Provision in the United Kingdom. Retrieved from http://journals.sagepub.com/doi/10.1177/1077801206289132

Hayati, E.N. (2000). Kekerasan Terhadap Istri. Yogyakarta : Rifka Annisa Women's Crisis Center.

Harrington, A., \& and Marshall, B. (2006). Encyclopedia of Social Theory. p. 420.

Howard, L. M., Trevillion, K., \& Agnew-Davies, R. (2010). Domestic violence and mental health. International Review of Psychiatry, 22(5), 525-534.

Hornby, A. S., \& Gatenby, E. V. (1960). The Advanced Learner's Dictionary of Current English. p.451.

Idrawan, A. (2017). BPS: Perempuan Kota Lebih Banyak Alami Kekerasan. Retrieved from http://nasional.republika.co.id/berita/nasional/hukum/17/03/30/onmc9s365-bps-perempuankota-lebih-banyak-alami-kekerasan

Jarvis, M. (2006). Sport psychology: A student's handbook. New York: Routledge.

Jayanthi, E.T. (2009). Faktor-Faktor Penyebab Terjadinya Kekerasan Dalam Rumah Tangga Pada

Survivor Yang Ditangano Oleh Lembaga Sahabat Perempuan Magelang. DIMENSIA, Volume

3, No. 2.

Kolibonso, R. S, Purniati. (2003). Menyingkapi Tirai Kekerasan dalam Rumah Tangga.Jakarta Mitra Perempuan. 
Kristyanti, S.R. (2004). Memahami Dinamika Kekerasan Pada Perempuan Korban KDRT. UPB :

Bogor.

Kumar, R. (1996). Research Methodology A Step by Step Guide for Beginners. London : Sage Publication.

Landgarten, H. B. (1981). Clinical Art Therapy A Comprehensive Guide. New York : Bruner/Mazel publishers.

Levick, M. (1981). Art Therapy : Handbook of innovative psychotherapies. New York: John Wilely \& Sons.

Machover, Karen. (1978). Personality Projection In The Drawing Of Human

Figure.Springfield.

Illinois.USA

Matud, M, P. (2005). The psychological impact of domestic violence on Spanish women. Journal of Applied Social Psychology, 35 (11).

Malchiodi, A. (2003). Handbook of Art therapy. New York: Guilford Press

McCaw, B., Golding, J. M., Farley, M., \& Minkoff, J. R. (2007). Domestic violence and abuse, health status, and social functioning. Women \& Health, 45(2), 1 -23.

Nevid, J. F., dkk. (2005). Psikologi Abnormal. Jakarta: Erlangga.

Ormrod, J. E. (2003). Educational Psychology: Developing Learners. Merrill Prentice Hall.

Pagelow, M. D. (1984). Family Violence. New York : Praeger.

Poerwandari, E. K., \& Lianawati, E. (2010). Buku saku untuk penegak hukum :

Petunjuk penjabaran kekerasan psikis untuk menindaklanjuti laporan kasus KDRT Jakarta : Program Studi Kajian Wanita Universitas Indonesia.

Puspitasari, M. P. (2015). Penerapan Art Therapy Pada Anak Korban Kekerasan Dalam Rumah Tangga Disertai Gejala Gangguan Stress Pasca Trauma. Universitas Gadjah Mada

Rappaport, L. (2009). Focusing-oriented art therapy: accessing the body's wisdom and creative intelligence. London: Jessica Kingsley.

Robertson, K., \& Murachver, T. (2007). It takes two to tangle: Gender symmetry in intimate partner violence. Basic and Applied Social Psychology, 29(2), 109-118.

Rubin, J.A. (2010). Introduction to Art Therapy: Source and Resources. New York: Taylor and Francis Group

Salcioglu, E., Urhan, S., Pirinccioglu, T., \& Aydin, S. (2017). Anticipatory fear and helplessness predict PTSD and depression in domestic violence survivors.

Psychological Trauma: Theory, Research, Practice, and Policy,9(1), 117-125. doi: $10.1037 / \operatorname{tra} 0000200$

Satiadarma, M. P. (2000). Dasar-dasar Psikologi Olahraga. Jakarta : Pustaka Sinar Harapan.

Septiani, Y.A., \& Adiyani, M. G. (2017). Art Therapy Berbasis CBT Untuk Menurunkan Agresivitas Anak Korban Kekerasan Dalam Rumah Tangga. Jurnal Psikologi Indonesia. Juni, Vol XII, No.1

Sharf, R.S. (2008). Theories of Psychotherapies and Counseling: Concepts and Cases. 5th Edition. Brooks/Cole. Belmont, CA 94002. USA.

Spielberger, C. D. (1972). Current trends in theory and research on anxiety. In C. D. Spielberger (Ed.), Anxiety: Current trends in theory and research (pp. 3-9). New York and London: Academic Press.

Stewart, C. J., \& Cash, W. B. (2000). Interviewing: Principles and practices. USA: McGraw Hill Company.

Straus, M. A., Gelles, R., \& Steinmetz, S. (1980). Behind closed doors: Violence in the American 
family. New York. Anchor Books.

Stuart, G. W. \& Sundeen, S .J. 1998. Principles and Practice of Psychiatric Nursing. 6th ed. St. Louis: Mosby Year Book.

Suliswati. (2005). Konsep Dasar Keperawatan Jiwa. Jakarta : EGC.

Sulastri, E., dan Retnowati, S. 2003. Studi Eksploratif tentang Kekerasan terhadap Perempuan dalam Rumah Tangga di Kabupaten Indramayu Jawa Barat. Psikologika. Yogyakarta:

\section{Fakultas}

Psikologi Universitas Islam Indonesia. Nomor 16, tahun VIII (30-40).

Sussman, M. B., \& Steinmetz, S. (1999). Handbook of Marriage and the Family. p. 713.

Talwar, S. (2007). Accessing traumatic memory through art making: An art therapy trauma protocol (ATTP). The Arts in Psychotherapy, 34(1), 22-35.Hill.

Tandon, Neeru. (2008). Feminism. A Paradigm Shift. pp.23-24.

Taylor, S.E. (1995). Health psychology. Singapore : Mc. Graw-Hill Book Co.

Videman, H. 2007. Kecemasan Atlet Sepakbola Tim Persija Junior. Skripsi. Fakultas Psikologi. Universitas Indonesia.

Wadeson, H. (1980). Art Psychotherapy. (2nd ed.). Hoboken, NJ: John Wiley \& Sons

York, M. R., 2011. Gender Attitudes and Violence against women. El Paso: LFB Scholarly Publishing. 